\title{
Sensometric calibration of sensory characteristics of commercially available milk products with instrumental data
}

\author{
H. Ochi, ${ }^{* 1}$ M. Sumi, † I. Nakata, ${ }^{*}$ H. Saito, ${ }^{*}$ M. Uozumi, † and K. Iwatsuki \\ ${ }^{*}$ Food Science \& Technology Institute and \\ †Product Evaluation Center, Morinaga Milk Industry Co. Ltd., 1-83, 5-Chome Higashihara Zama, Kanagawa 228-8583, Japan
}

\begin{abstract}
Seven brands of commercial milk and related products that are available in the Japanese market were investigated. Quantitative descriptive analysis was used to describe 12 sensory properties of the samples, and the position of each sample was displayed by principal component analysis. The sensory descriptors of the samples were correlated with various analytical data by partial least squares regression analysis. Aroma descriptors were correlated with the headspace gas chromatography-mass spectrometry profile. Descriptors of flavor, mouthfeel, and aftertaste were correlated with the results of the physicochemical analysis. Many of the volatile compounds that contributed to aroma attributes, according to the partial least squares loading plot, were in agreement with the influence of volatile compounds shown by previous studies. Lactulose and furosine, as indicators of heating, and viscosity were parameters that influenced flavor, mouthfeel, and aftertaste. In addition, overall aftertaste was significantly related to fat content.
\end{abstract}

Key words: commercial milk, quantitative descriptive analysis, principal component analysis, partial least squares regression analysis

\section{INTRODUCTION}

Milk has long been known as an important source of nutrients such as protein, minerals, and vitamins. Extensive research, including both analytical and sensory analysis, has been conducted on milk produced under various conditions.

Because product quality drives consumer acceptance and demand, the ability to measure the sensory attributes characteristic of a product and to correlate these with consumer preference or data from instrumental analysis is necessary for the development and production of products that can meet consumer expectations.

Received July 16, 2009.

Accepted December 22, 2009

${ }^{1}$ Corresponding author: h_oti@morinagamilk.co.jp
Today, descriptive analysis has gained wide acceptance as one of the most important tools for studying issues related to the appearance, flavor, and texture of products, and as a guide to product development. Descriptive analysis is a sensory testing method that provides quantitative descriptions of products based on the perceptions of a group of qualified subjects. A quantitative descriptive analysis approach has been applied in the sensory evaluation of conventional pasteurized milk (Phillips et al., 1995; Quinones et al., 1998; Chapman and Boor, 2001; Chapman et al., 2001).

Pasteurized or sterilized milk is obtained either by a low-temperature, long-time (LTLT) pasteurization process, HTST pasteurization process, or a UHT sterilization process. Ultra-high temperature processing can involve either direct or indirect heating. Ultra-high temperature sterilized milk is widely used in many countries around the world. Most of the UHT milk products on the market in Japan are sterilized by a plate heatexchanger indirect heating system. Direct heating systems involve steam infusion or steam injection, whereby the milk is rapidly raised to an ultra-high temperature by direct mixing with steam, followed immediately by rapid cooling through flash vacuum evaporation of water that has condensed from the steam (Stroup et al., 1972; Blake et al., 1995). Heating processes could significantly affect the sensory properties of milk. Heat treatments, particularly UHT processing, can promote the development of thermally derived off-flavor compounds such as aldehydes, methyl ketones, and various sulfur compounds (Jeon et al., 1978; Moio et al., 1994; Contarini et al., 1997; Contarini and Povolo, 2002). Direct heat sterilization results in less thermal damage compared with indirect heat sterilization (Elliott et al., 2005); therefore, steam infusion is used to produce high-quality commercial milk products that can be differentiated from other milk products in the Japanese market. There is also another method for producing high-quality commercial milk. Dissolved oxygen is removed before UHT sterilization to minimize development of an off-flavor by an oxidative reaction. To better meet consumer requests for palatability, some commercial milk products created by the special pro- 
Table 1. Nutritional information of sample milks as listed on the product packages

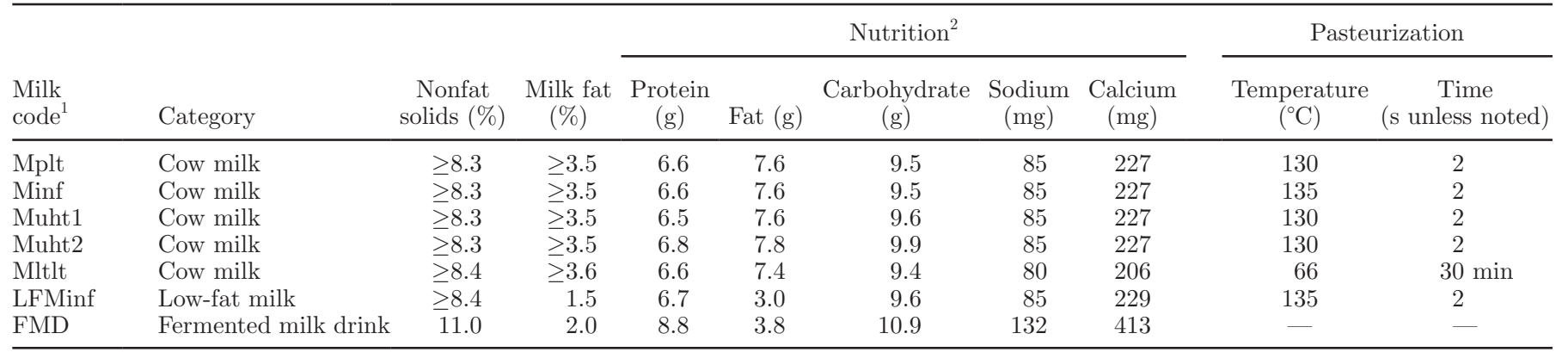

${ }^{1}$ Mplt = full-cream milk, UHT plate heat exchanger pasteurized; Minf = full-cream milk, UHT steam infusion sterilized; Muht1, Muht2 = fullcream milk, supposed to be UHT plate heat exchanger sterilized, dissolved oxygen content reduced before sterilization; Mltlt = full-cream milk, low-temperature, long-time pasteurized; LFMinf = low-fat milk, UHT steam infusion sterilized; FMD = fermented milk drink.

${ }^{2}$ Per $180 \mathrm{~mL}$ for FMD; per $200 \mathrm{~mL}$ for all other products.

cesses mentioned above have been recently introduced into the Japanese market.

Consumers can now choose from specialty milks and conventional milk, LTLT pasteurized milk, low-fat milk, and fermented milk drinks when they purchase milk. Some of the authors of the current study have reported that UHT (conventional plate heat-exchanger sterilization) milk tended to be preferred to LTLT milk and HTST milk when the effect of pasteurization and UHT processing conditions on the sensory characteristics and preference of milk was examined. It seems that flavor familiarity is one of the significant factors that affects the degree of palatability (Iwatsuki et al., 1999b).

What kind of descriptive sensory profile does the familiar flavor have? In contrast, how different are the sensory characteristics of the various processing types of milk products in the current market from the conventional plate heat-exchanger UHT milk (which has the familiar flavor)? In addition, how different from the milk mentioned above are the sensory characteristics of the low-fat milk and fermented milk drinks competing for market share?

To our knowledge, no published information concerning sensory characteristics of the latest Japanese representative commercially available milk products has employed descriptive analysis to solve the problems mentioned above. Upon successful clarification of these issues, if we reveal correlations between sensory attributes and laboratory instrumental measurements we would obtain significant information for interpreting sensory profiles.

Therefore, the objectives of this study were to 1) profile the sensory characteristics of the representative commercially available milk products in the current Japanese market, including full-cream milks produced via various pasteurization and sterilization processes, low-fat milk, and a fermented milk drink using descriptive analysis, and 2) determine relationships between the sensory properties of representative commercial milk and laboratory measurements, by partial least squares (PLS) regression analysis, to interpret the sensory attributes developed in those sample categories.

\section{MATERIALS AND METHODS}

\section{Milk Samples}

Seven milk products were purchased from a local market in Kanagawa prefecture, Japan. All were domestic products sold in the Japanese market. Each milk product was selected 3 times from the local market. The product nutrition information and sample codes are listed in Table 1.

Five varieties of full-cream milk were used for sensory and instrumental analysis: UHT steam infusion sterilized (Minf), UHT plate heat exchanger sterilized (Mplt), supposed to be UHT plate heat sterilized (Muht1, Muht2), and low-temperature, long time pasteurized (Mltlt). Additionally, 1 low-fat milk, UHT steam infusion sterilized (LFMinf), was used. One fermented milk drink (FMD), which is categorized as a milk product according to Japan's regulations (Ministry of Health, Labor and Welfare, Japan, 1951), was also subjected to sensory evaluation and instrumental analysis. Because the fermented milk drink in this study was set at a neutral $\mathrm{pH}$, it had no acidic flavor. For the Muht1 and Muht2 samples from different manufacturers, the dissolved oxygen content was reduced before sterilization. An expiration date was provided for only the milk products. The milk products were evaluated more than $3 \mathrm{~d}$ before the expiration date.

\section{Descriptive Sensory Analysis}

Quantitative descriptive sensory analysis (Stone and Sidel, 2004) was performed to evaluate 5 full-cream milk 
Table 2. Sensory attributes tested by the panel

\begin{tabular}{lll}
\hline Modality & Attribute & Characteristic \\
\hline Appearance & Yellow App & Yellowish appearance \\
Aroma & Overall Ar & Overall intensity of orthonasal aroma \\
& Butter Ar & The orthonasal aroma of butter \\
Flavor & Cooked Fl & Typical retronasal aroma and taste generated by cooked milk \\
& Sweet Fl & The taste associated with lactose \\
& Fatty Fl & Fresh cream-like \\
& Milky Fl & Typical flavor of fresh milk \\
Mouthfeel & Salty Fl & Salty taste \\
& Body Mf & Thick and rich \\
& Smooth Mf & Easy to drink \\
Aftertaste & Sticky Mf & Sticky in the mouth, especially on the tongue \\
\hline
\end{tabular}

samples, 1 low-fat milk sample, and 1 fermented milk drink using a 15-cm horizontal line with directional terms (e.g., weak, strong) located $13 \mathrm{~mm}$ from each end. Evaluation was performed by a trained panel that consisted of 12 members (aged 20 to $30 \mathrm{yr} ; 8$ females and 4 males). They were selected based on their ability to detect 5 basic tastes (salty, sweet, acidic, bitter, and umami) and to identify differences between the milk products using the triangle test. Using quantitative descriptive analysis methodology, terms for the evaluation of the milk samples were developed by the panel. The descriptive terms for each major sensory category are listed in Table 2. Ballot development and panelist training were accomplished during 6 working sessions, each lasting for approximately $90 \mathrm{~min}$. Eighty milliliters of milk, at approximately $7^{\circ} \mathrm{C}$, was placed in a $110-\mathrm{mL}$ plastic cup and served to a panelist. Quantitative descriptive analysis was performed using the 12 sensory attributes listed in Table 2 for all 7 samples. A balanced block (Macfie et al., 1989) order of samples and panelists was used to avoid an order effect. All samples were evaluated 3 times. Samples were identified by a 3 -digit random number when presented to the panel. The entire evaluation was conducted in a sensory evaluation room at the Research and Information Center of Morinaga Milk Industry Co. Ltd (Kanagawa, Japan) that was air conditioned and free from external aromas, noise, and distraction,.

\section{GC-MS Analysis}

A $10-\mathrm{mL}$ aliquot of milk was placed in a $20-\mathrm{mL}$ glass vial that was set in an autosampler and heated at $35^{\circ} \mathrm{C}$ for $30 \mathrm{~min}$ by a sample heater to isolate headspace volatile substances, which were adsorbed by a solid-phase microextraction (SPME) in an SPME Fiber Assembly (50/30- $\mu \mathrm{m}$ DVB/Caroxen/PDMS StableFlex for Auto Holder, Supelco, St. Louis, MO). The adsorbed compounds were then released by heating at $265^{\circ} \mathrm{C}$ for 3 min using $\mathrm{He}$ gas at $1 \mathrm{~mL} / \mathrm{min}$ and were automatically injected into a GC 6890 gas chromatograph (Agilent Technologies, Palo Alto, CA) with an HP-INNOWax fused silica capillary column $(30 \mathrm{~m} \times 0.25 \mathrm{~mm}$ i.d., $0.25 \mu \mathrm{m}$ film thickness; Agilent Technologies) that was coupled with an MS-5973 mass spectrometer. The oven temperature was increased from 40 to $120^{\circ} \mathrm{C}$ at $4^{\circ} \mathrm{C} / \mathrm{min}$ and from 120 to $250^{\circ} \mathrm{C}$ at $6^{\circ} \mathrm{C} / \mathrm{min}$. The flow-rate of $\mathrm{He}$ (the carrier gas) was $0.5 \mathrm{~mL} / \mathrm{min}$. Gas chromatography-MS was done at an ionization voltage of $70 \mathrm{eV}$ and with an ion source temperature of $230^{\circ} \mathrm{C}$. Peaks were identified by matching their mass spectra with those in the Wiley Library of MS spectra (Agilent Technologies) and by their retention indices. To be precise, the volatile compounds in this study are tentatively identified because authentic compounds are not used to verify mass spectra and retention times or retention indices. Peak areas were calculated by computer and used for statistical analysis.

\section{Physicochemical Analysis}

Protein and fat contents were measured by Fouriertransformed infrared analysis with a MilkoScan FT120 (Foss Japan Ltd., Tokyo, Japan). Analysis of lactose was carried out by normal-phase HPLC (Shimadzu Corporation, Kyoto, Japan) using a Shodex DC-613 column $(150 \mathrm{~mm} \times 6.0 \mathrm{~mm}$ i.d.; Showa Denko KK, Tokyo, Japan). Elution was done with a mobile phase containing $75 \%$ acetonitrile at a flow-rate of $1.2 \mathrm{~mL} /$ min, and the eluate was monitored with a refractive index (RI) detector.

Analysis of frosine was carried out by reverse-phase HPLC (Hitachi High-Technologies Corporation, Tokyo, Japan) using an ODS C18 column $(250 \mathrm{~mm} \times 4.6 \mathrm{~mm}$ i.d.; Mightysil RP-18, Kanto Chemical Co. Inc., Tokyo, Japan) after acid hydrolyzation. Elution was performed with a mobile phase containing $0.1 M$ phosphate buffer (pH 6.0) and acetonitrile (2.5:1) as well as $15 \mathrm{~m} M$ SDS. The flow-rate was $1.0 \mathrm{~mL} / \mathrm{min}$, and UV detection was done at $280 \mathrm{~nm}$ (Watanabe et al., 1995). 


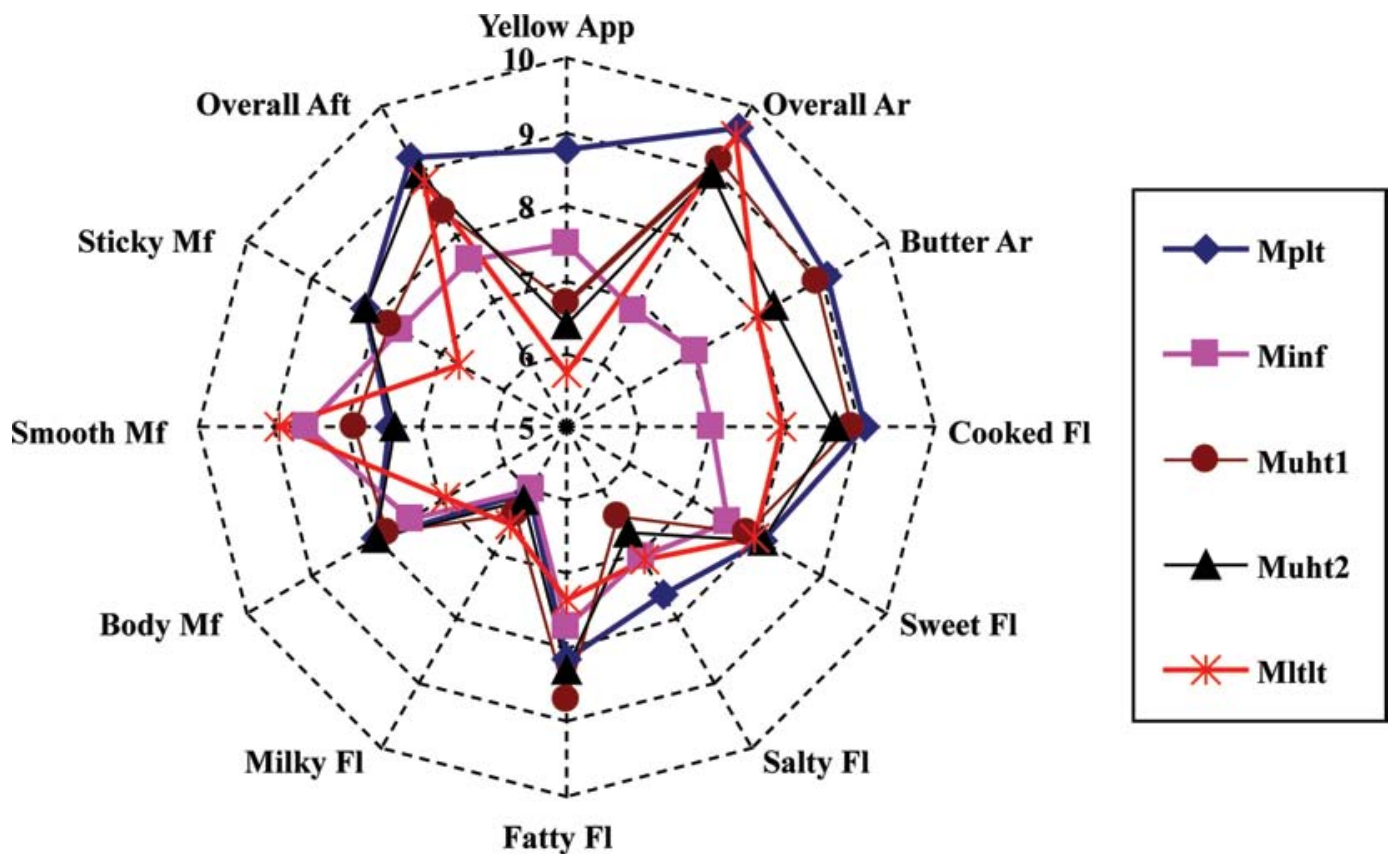

Figure 1. Spider plots of the sensory properties of the full-cream milk samples with various sterilization and pasteurization processes. Mplt: full-cream milk, UHT plate heat exchanger sterilized; Minf: full-cream milk, UHT steam infusion sterilized; Muht1, Muht2: full-cream milk, supposed to be UHT plate heat exchanger sterilized, dissolved oxygen content reduced before sterilization; Mltlt: full-cream milk, low-temperature, long-time pasteurized. See Table 2 for descriptions of sensory attributes. Color version available in the online PDF.

Analysis of lactulose was carried out after separation of sugar borate complexes by anion exchange HPLC (Hitachi High-Technologies Corporation) using TSKgel Sugar AXI $(150 \mathrm{~mm} \times 4.6 \mathrm{~mm}$ i.d.; Tosoh Corporation, Tokyo, Japan) with postcolumn fluorescence (Mikami and Ishida, 1983). Elution was done with a mobile phase of $0.5 M$ borate buffer $(\mathrm{pH} 8.7)$ at a flow-rate of 0.4 $\mathrm{mL} / \mathrm{min}$ and with a reaction solution consisting of $1 \%$ Arg and $3 \%$ borate $(\mathrm{pH} 7.4)$ at a flow-rate of $0.5 \mathrm{~mL} /$ min. Monitoring was done with a fluorescent detector (excitation at $320 \mathrm{~nm}$ and emission at $430 \mathrm{~nm}$ ). The $\mathrm{pH}$ of each sample was measured with a $\mathrm{pH}$ meter (F-52, Horiba Ltd., Kyoto, Japan).

Viscosity was measured with a CJV-5000 vibroviscometer (A \& D Co. Ltd., Tokyo, Japan), which vibrated at a frequency of $30 \mathrm{~Hz}$ and an amplitude of 50 $\mathrm{mV}$. The sensor plates were immersed in a sample at $10^{\circ} \mathrm{C}$. After a stabilization period of $30 \mathrm{~s}$, the electrical current from the sensor plates was measured and viscosity was calculated.

Total milk solids (TMS) contained in a $2-\mathrm{mL}$ aliquot of each sample were measured with a microwave solid analyzer (Smart System 5, CEM Corporation, Matthews, NC) using the constant weight method. Fat globule size was measured with a laser scattering particle size distribution analyzer (LA-500, Horiba Ltd.) over the range of 0.1 to $200.0 \mu \mathrm{m}$.

\section{Statistical Analysis}

Multivariate analysis of the results was performed. Multiple comparisons (Tukey's HSD test) was carried out with JMP software (SAS Institute, Cary, NC). Principal component analysis and PLS analysis were performed with XLSTAT software (Addinsoft Inc., Brooklyn, NY) to analyze the descriptive and instrumental data. The correlations between scores for individual sensory attributes and measurements were investigated by PLS1 analysis, whereas the correlations between overall sensory attributes and measurements were analyzed by PLS2 analysis.

Data, such as the composition of milk products, GCMS peak areas, and the scores for sensory attributes, were measured in triplicate, averaged, and transformed so that each variable had a unit variance and zero mean before performing PLS analysis to obtain an unbiased contribution of each variable to the $\mathrm{Y}$ variable. By applying PLS analysis to the transformed data, the importance of peaks and components for each attribute could be compared quantitatively based on regression coefficients and loading weights for each predictor or $\mathrm{X}$ variable used in the PLS models. The experimental design for sensory analysis was a balanced block design, and the experimental design for instrumental analysis was a randomized block design. 


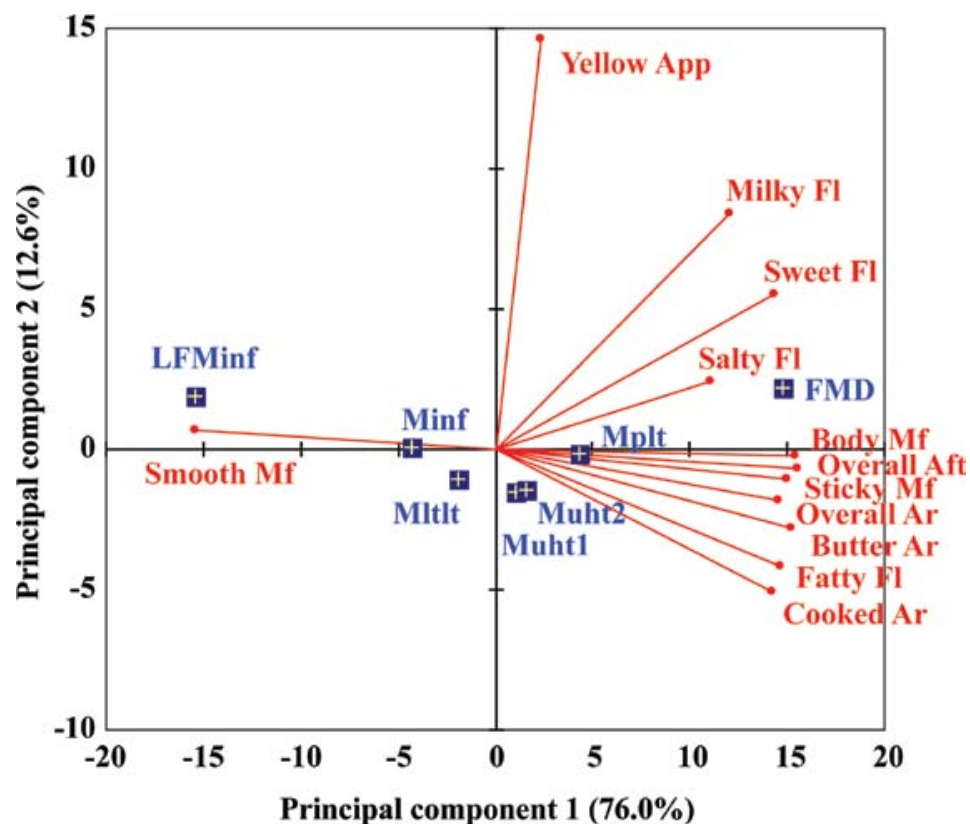

Figure 2. Spider plots of the sensory properties of the samples with UHT plate heat exchanger sterilization, low-fat milk, and fermented milk drink. Mplt: full-cream milk, UHT plate heat exchanger sterilized; LFMinf: low-fat milk, UHT steam infusion sterilized; FMD: fermented milk drink. See Table 2 for descriptions of sensory attributes. Color version available in the online PDF.

\section{RESULTS AND DISCUSSION}

\section{Descriptive Sensory Analysis}

Figures 1 and 2 show the sensory profiles of each milk sample. To create a visual profile of product attributes, spider plots were made by plotting average intensity on each scale. Figure 1 shows the full-cream milk samples that have almost the same composition and are expected to have subtle differences; therefore, the scale of the plot is expanded (a different scale was adopted for Figures 1 and 2). Most of the milk products marketed in Japan are sterilized by a plate heat exchanger indirect heating system. Therefore, the code Mplt in Figures 1 and 2 was a control sample for commercial milk; the profile of that is the so-called familiar flavor.
As shown in Figure 1, among the full-cream milk samples, the steam infusion sterilized sample had lower scores for aroma attributes such as overall aroma (Overall Ar), butter aroma (Butter Ar), and cooked flavor (Cooked Fl), whereas it had a higher score for smooth mouthfeel (Smooth Mf). The other attributes were almost the same, except for yellow appearance (Yellow App). The low-temperature, long-time pasteurized sample had lower scores for aroma attributes than the conventional plate heat-exchanger sterilized sample, whereas the steam infusion sterilized sample had still lower scores. The low-temperature, long time pasteurized sample had the same score as the steam infusion sterilized sample for Smooth Mf, whereas the low-temperature, long time pasteurized sample

Table 3. Multiple comparisons of samples for each sensory attribute ${ }^{1}$

\begin{tabular}{|c|c|c|c|c|c|c|c|c|c|c|c|c|}
\hline Item $^{2}$ & Yellow App & Overall Ar & Butter Ar & Cooked Fl & Sweet Fl & Fatty Fl & Milky Fl & Salty Fl & Body Mf & Smooth Mf & Sticky Mf & Overall Aft \\
\hline Mplt & $\mathrm{b}$ & $\mathrm{b}$ & $a, b$ & $\mathrm{a}$ & $\mathrm{b}$ & $a, b, c$ & $\mathrm{~b}$ & $\mathrm{a}$ & $\mathrm{b}$ & $\mathrm{c}, \mathrm{d}$ & $\mathrm{b}, \mathrm{c}$ & $\mathrm{b}$ \\
\hline Minf & $\mathrm{c}$ & $\mathrm{c}$ & $c$ & $\mathrm{~b}, \mathrm{c}$ & $\mathrm{b}, \mathrm{c}$ & $\mathrm{b}, \mathrm{c}$ & $\mathrm{b}$ & $a, b$ & $\mathrm{~b}$ & $\mathrm{~b}, \mathrm{c}$ & $a, b$ & $\mathrm{c}$ \\
\hline Muht1 & $\mathrm{c}, \mathrm{d}$ & $\mathrm{b}$ & $a, b$ & $\mathrm{a}$ & $\mathrm{b}, \mathrm{c}$ & $a, b$ & $\mathrm{~b}$ & $\mathrm{~b}$ & $\mathrm{~b}$ & $\mathrm{~b}, \mathrm{c}$ & $\mathrm{b}, \mathrm{c}$ & $\mathrm{b}, \mathrm{c}$ \\
\hline Muht2 & $\mathrm{c}, \mathrm{d}$ & $\mathrm{b}$ & $\mathrm{b}, \mathrm{c}$ & $\mathrm{a}$ & $\mathrm{b}$ & $\mathrm{a}, \mathrm{b}, \mathrm{c}$ & $\mathrm{b}$ & $a, b$ & $\mathrm{~b}$ & $\mathrm{c}, \mathrm{d}$ & $a, b$ & $\mathrm{~b}, \mathrm{c}$ \\
\hline Mltlt & $\mathrm{d}$ & $\mathrm{b}$ & $\mathrm{b}, \mathrm{c}$ & $a, b$ & $\mathrm{~b}, \mathrm{c}$ & $\mathrm{c}$ & $\mathrm{b}$ & $a, b$ & $\mathrm{~b}$ & $\mathrm{~b}$ & $\mathrm{c}$ & $\mathrm{b}, \mathrm{c}$ \\
\hline LFMinf & $a, b$ & $\mathrm{c}$ & $\mathrm{d}$ & $\mathrm{c}$ & $\mathrm{c}$ & d & $\mathrm{b}$ & $\mathrm{b}$ & $\mathrm{c}$ & $\mathrm{a}$ & $\mathrm{d}$ & d \\
\hline FMD & $\mathrm{a}$ & $\mathrm{a}$ & $\mathrm{a}$ & $\mathrm{a}$ & $\mathrm{a}$ & $\mathrm{a}$ & $\mathrm{a}$ & $\mathrm{a}$ & $\mathrm{a}$ & d & $\mathrm{a}$ & $\mathrm{a}$ \\
\hline
\end{tabular}

${ }^{\mathrm{a}-\mathrm{d}}$ Means with the same letter(s) are not significantly different at $P<0.05$

${ }^{1}$ See Table 2 for descriptions of sensory attributes.

${ }^{2} \mathrm{Mplt}=$ full-cream milk, UHT plate heat exchanger pasteurized; Minf = full-cream milk, UHT steam infusion sterilized; Muht1, Muht2 = fullcream milk, supposed to be UHT plate heat exchanger sterilized, dissolved oxygen content reduced before sterilization; Mltlt = full-cream milk, low-temperature, long-time pasteurized; LFMinf = low-fat milk, UHT steam infusion sterilized; FMD = fermented milk drink. 


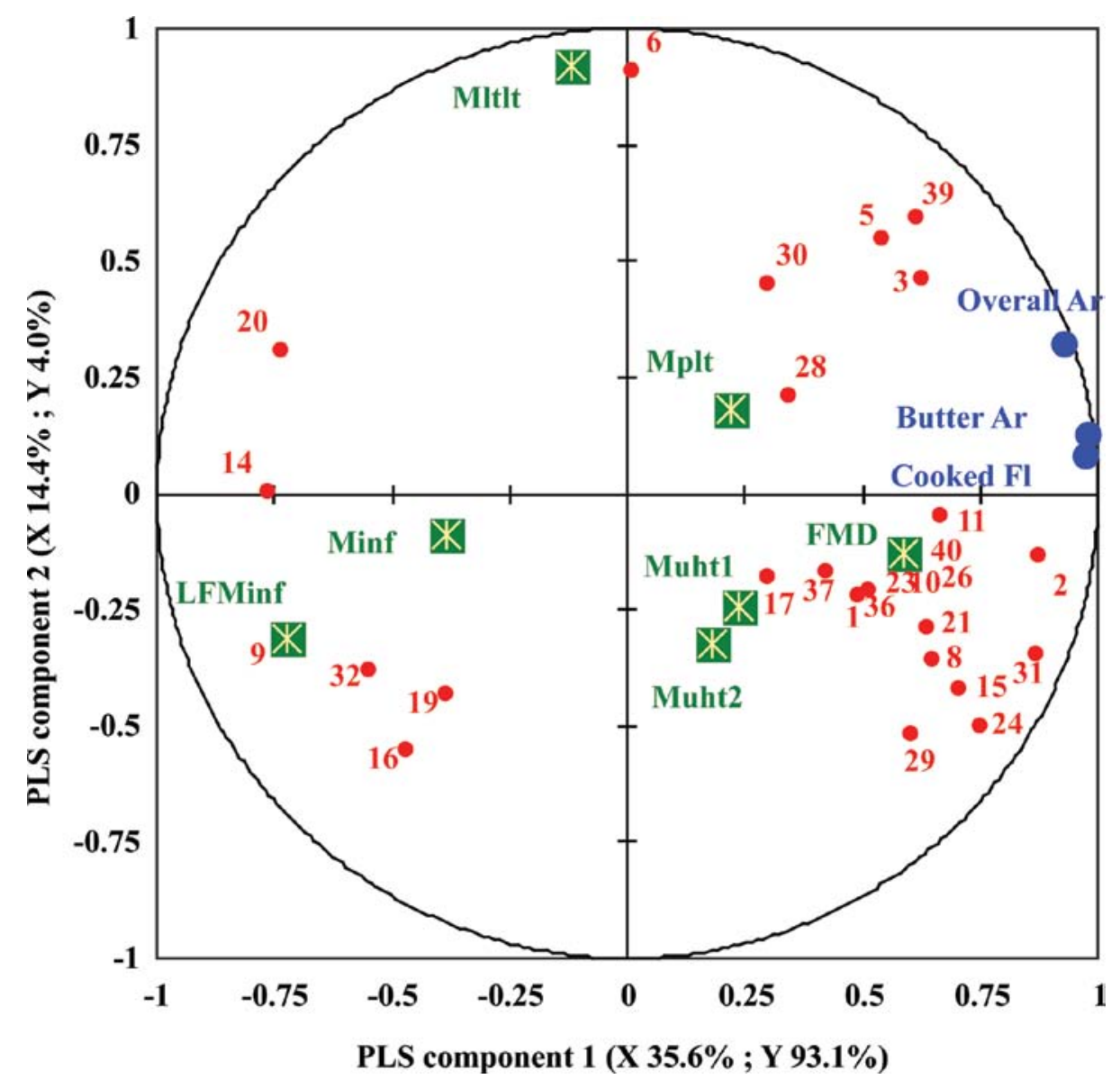

Figure 3. Biplot of scores and factor loadings obtained by principal component analysis for all 7 samples. Mplt: full-cream milk, UHT plate heat exchanger sterilized; Minf: full-cream milk, UHT steam infusion sterilized; Muht1, Muht2: full-cream milk, supposed to be UHT plate heat exchanger sterilized, dissolved oxygen content reduced before sterilization; Mltlt: full-cream milk, low-temperature, long-time pasteurized; LFMinf: low-fat milk, UHT steam infusion sterilized; FMD: fermented milk drink. See Table 2 for descriptions of sensory attributes. Color version available in the online PDF.

had a lower score for sticky mouthfeel (Sticky Mf) than either the steam infusion sterilized sample or the conventional plate heat-exchanger sterilized sample. Among the 5 full-cream milk samples, Tukey's HSD test showed statistically significant differences $(P<$ 0.05 ) between the products for 9 attributes, except for sweet flavor (Sweet Fl), milky flavor (Milky Fl), and body mouthfeel (Body Mf) as shown in Table 3.

A comparison between the conventional plate heatexchanger sterilization, the low-fat milk steam infusion sterilization, and the fermented milk drink is shown in Figure 2. The low-fat milk steam infusion sterilization and the fermented milk drink had a diagnostic value. Sensory evaluation space was expanded by the fermented milk drink showing high scores for Sweet Fl, Milky Fl, Body Mf, and overall aftertaste (Overall Aft). In the case of the low-fat milk steam infusion sterilization, fatty flavor (Fatty Fl), Body Mf, Sticky Mf, and Overall Aft showed lower scores, whereas Smooth Mf was higher than for any other sample.
Two principal components (PC) that accounted for 88.6\% (PC1:76.0\%; $\mathrm{PC} 2: 12.6 \%$ ) of the total variance were extracted by PC analysis. Figure 3 shows a biplot on which the fermented milk drink and steam infusion sterilized low-fat milk are located near both ends of the PC1 axis, whereas the other samples are located between these 2. Principal component 1 showed a strong positive correlation with many sensory attributes, including Body Mf, Overall Aft, Sticky Mf, Overall Ar, and Butter Ar, whereas it had a strong negative correlation with Smooth Mf.

\section{Relation Between Aroma Attributes and GC-MS Data}

Volatile compounds in milk have been extensively studied using several extraction techniques. In this study, SPME was adopted. This technique can substantially reduce analysis time and sample manipulation steps, and it has, therefore, been widely used to extract volatile components from dairy foods, including milk 


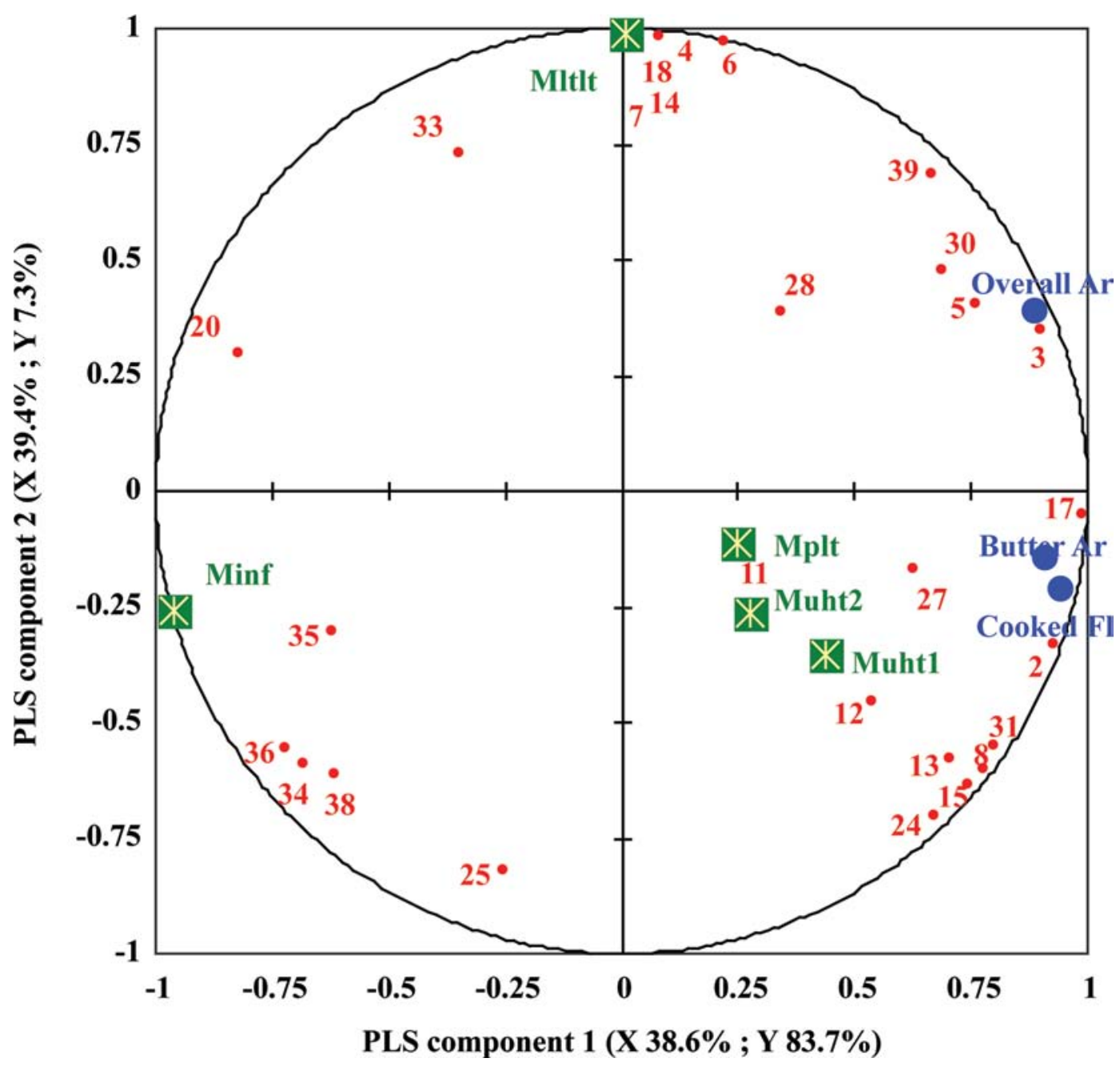

Figure 4. Correlation circle, for all 7 samples, of the sensory aroma attributes, GC-MS peaks (numbered dots), and the products with (PLS component 1, PLS component 2). PLS: partial least squares; Mplt: full-cream milk, UHT plate heat exchanger sterilized; Minf: full-cream milk, UHT steam infusion sterilized; Muht1, Muht2: full-cream milk, supposed to be UHT plate heat exchanger sterilized, dissolved oxygen content reduced before sterilization; Mltlt: full-cream milk, low-temperature, long-time pasteurized; LFMinf: low-fat milk, UHT steam infusion sterilized; FMD: fermented milk drink. See Table 2 for descriptions of sensory attributes. Color version available in the online PDF.

(Adahchour et al., 1999; Fenaille et al., 2003; Pinho et al., 2003; Francis et al., 2005).

After PLS analysis of the GC-MS data for all 7 samples, 28 GC-MS peaks were selected as influential peaks according to their PLS loading weights, and a second PLS analysis was then performed. Partial least squares regression of the 3 sensory aroma (orthonasal and retronasal) attributes (Y variable) versus the 28 GC-MS peaks (X variable) using the first 2 components yielded the sensory characteristics (2 orthonasal aroma and Cooked $\mathrm{Fl}$ including retronasal aroma) versus measured data (volatile compounds) versus products map shown in Figure 4. Based on the coefficient of determination value and the coefficient of determination value for cross-validation, the correlation was excellent.
Figure 4 shows that there is a strong correlation among the 3 aroma attributes. Overall Ar, which is useful for quality control, is considered to be a composite of Butter Ar, Cooked Fl, and so on.

Figure 5 shows comparisons between full-fat milks (excluding the effects of the low-fat milk and fermented milk drink) in the same manner as shown in Figure 4. Partial least squares regression of the 3 sensory aromas (Y variable) versus the 27 GC-MS peaks for the 5 full-fat milk samples (X variable), using the first 2 components, yielded the sensory characteristics versus measured data (volatile compounds) versus products map.

Interestingly, even after the low-fat milk and the fermented milk drink, which seem to be outliers in the 


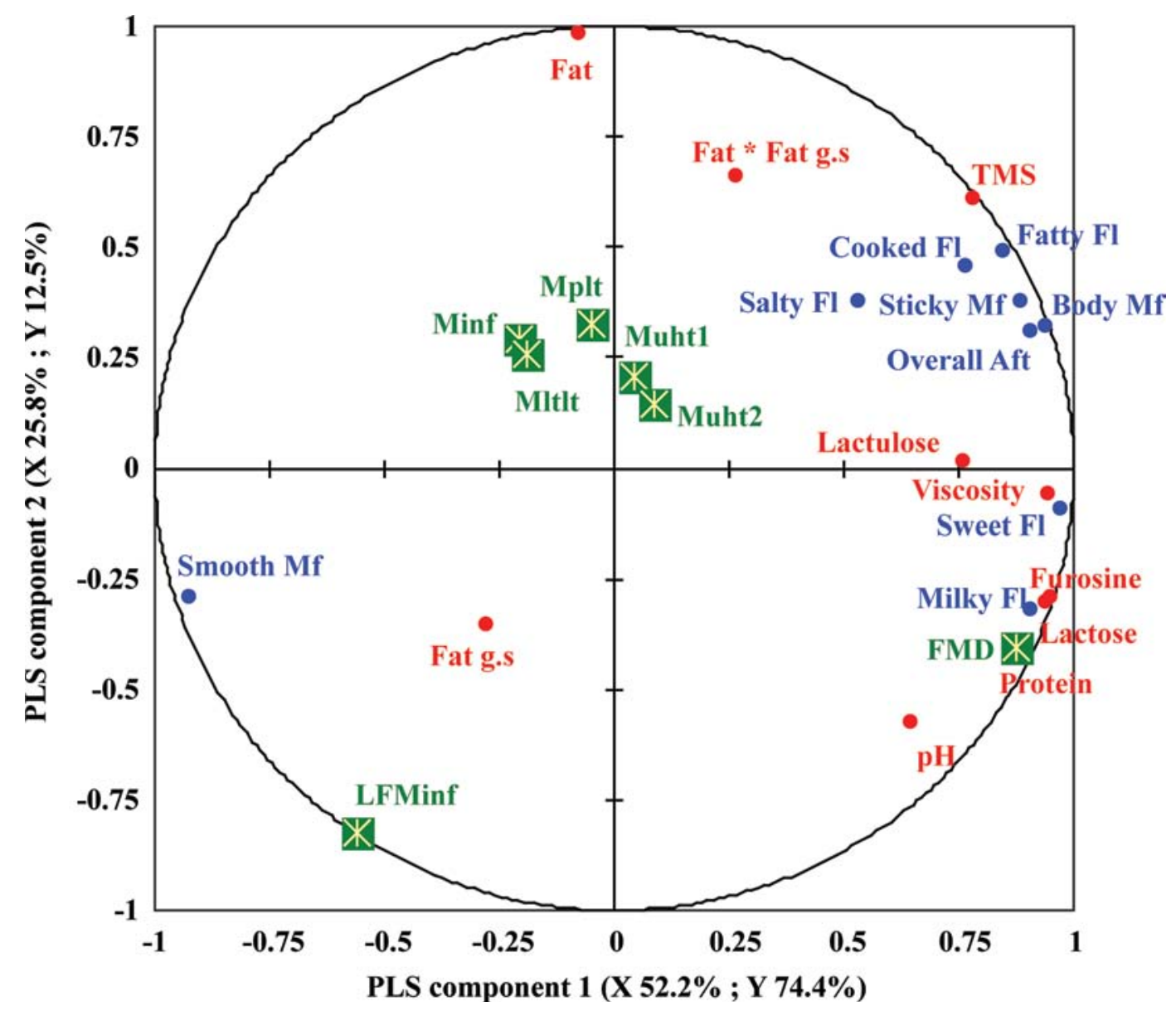

Figure 5. Correlation circle, for 5 full-cream milk samples, of the sensory aroma attributes, GC-MS peaks (numbered dots), and the products with (PLS component 1, PLS component 2). PLS: partial least squares; Mplt: full-cream milk, UHT plate heat exchanger sterilized; Minf: full-cream milk, UHT steam infusion sterilized; Muht1, Muht2: full-cream milk, supposed to be UHT plate heat exchanger sterilized, dissolved oxygen content reduced before sterilization; Mltlt: full-cream milk, low-temperature, long-time pasteurized. See Table 2 for descriptions of sensory attributes. Color version available in the online PDF.

data in Figure 4, were eliminated, it can be seen that PLS component 1 in Figure 5, which accounts for most of the variability in the data (approximately $84 \%$ ), differentiates largely between the steam infusion sterilized sample and other samples. The sensory characteristics of the infusion-sterilized milk reveal that cooked flavor and butter aroma are suppressed, leading to a refreshing overall aftertaste.

Figure 6 shows a scatter plot of factor loadings, based on all 7 samples, for 28 peaks and aromatic sensory attributes in the first and second PLS components. The importance of each peak can be compared on this plot as described below. First, draw a line from the aromatic attribute through the origin $(0,0)$ and then to the border on the other side of the origin. A perpendicular line drawn from the $i$ th GC-MS peak on this line projects the $i$ th peak point onto the line. The distance from the projection of $i$ th peak point to the origin is proportional to importance of $i$ th peak for aromatic attributes (Wold, 1995).

The volatile compounds correlated (positively or negatively) with each aroma attribute are ordered according to importance based on their factor loadings in Table 4. As above, a significant correlation was found among the 3 aroma attributes. As shown in Table 4, most of the peaks contributing markedly to Butter Ar and Cooked $\mathrm{Fl}$ were also significant peaks for Overall Ar. This confirmed that Overall Ar is principally composed of Butter Ar and aromatics of Cooked Fl. The volatile compounds shown in Figure 5 were confirmed by a previous study to be significant contributors to milk aroma according to GC-olfactometry and modified 

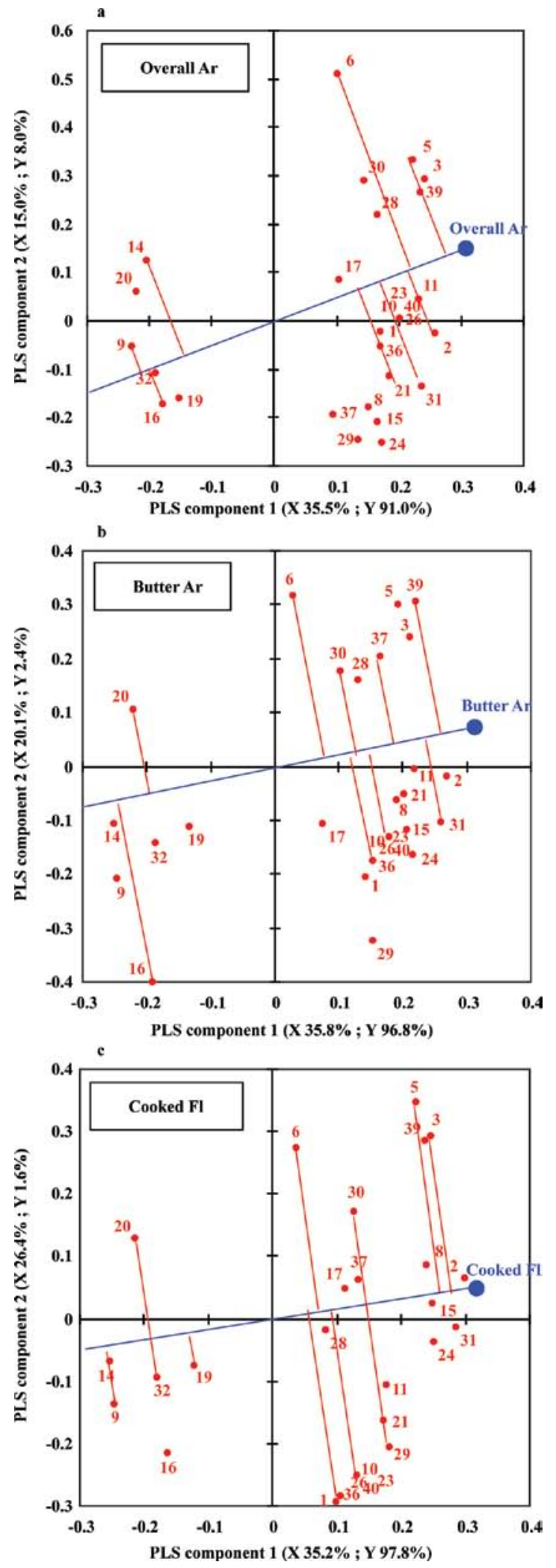

Figure 6. Partial least squares (PLS) loading plots, based on all 7 samples, of the GC-MS peaks for a) overall aroma, b) butter aroma, and c) cooked flavor. See Table 2 for descriptions of sensory attributes. Color version available in the online PDF. methods such as sniffing of diluted extracts. Among the volatile compounds in Table 4, descriptions of the odors of these compounds have been reported based on sniffing of diluted extracts analysis with a method called CharmAnalysis. It was reported that 2-undecanone was vegetable/rue-like and 2-heptanone was blue cheese/ mustard/spicy (Moio et al., 1994). In addition, using aroma extract dilution analysis, it was reported that decanoic acid was soapy/acidic/sweaty, 2-undecanone was fatty/green, octanoic acid was lactone-like, 2-heptanone was fruity/milky, and acetic acid was milky/ fatty (Iwatsuki et al., 1999a).

It has also been identified that dimethyl sulfide and dimethyl disulfide are related to a cooked off-flavor (i.e., sulfurous, cooked, cabbage-like aroma) in UHT milk (Vazquez-Landaverde et al., 2006). By the headspace SPME-GC technique, which is the same method as used in this study for quantitative analysis of heatderived "off" compounds in milk, it was suggested that 2-heptanone and dimethyl sulfide in Table 4 could be important contributors to the off-flavor, based on the calculated odor activity values (Vazquez-Landaverde et al., 2005).

Although it is difficult to simply compare these results with previous findings because of differences in the raw milk source, time after manufacturing, manufacturing conditions, and methods for extraction and concentration of aroma compounds, previous reports support the contribution of volatile compounds that were identified by the PLS approach. Therefore, our interpretation of the aroma properties is reasonable.

\section{Relation Between Sensory Attributes and Physicochemical Properties}

In the same manner as shown in Figure 4, PLS regression of the 9 sensory attributes (flavor, mouthfeel, and aftertaste; Y variable) versus the composition and physicochemical properties (X variable) using the first 2 components yields the sensory characteristics (flavor, mouthfeel, and aftertaste) versus measured data (composition and physicochemical properties) versus products map shown in Figure 7. When the coefficient of determination and the coefficient of determination value for cross-validation were calculated, a good correlation was shown. The coefficient of determination between Y and (PLS component 1, PLS component 2) was equal to 0.87 , and the coefficient of determination for cross-validation was 0.50 .

Investigation of the effect of the homogenization pressure on physicochemical properties and sensory characteristics has shown that a higher pressure leads to smaller fat globules and a lower pressure strengthens the sensory attributes of fattiness, body, milky taste, 


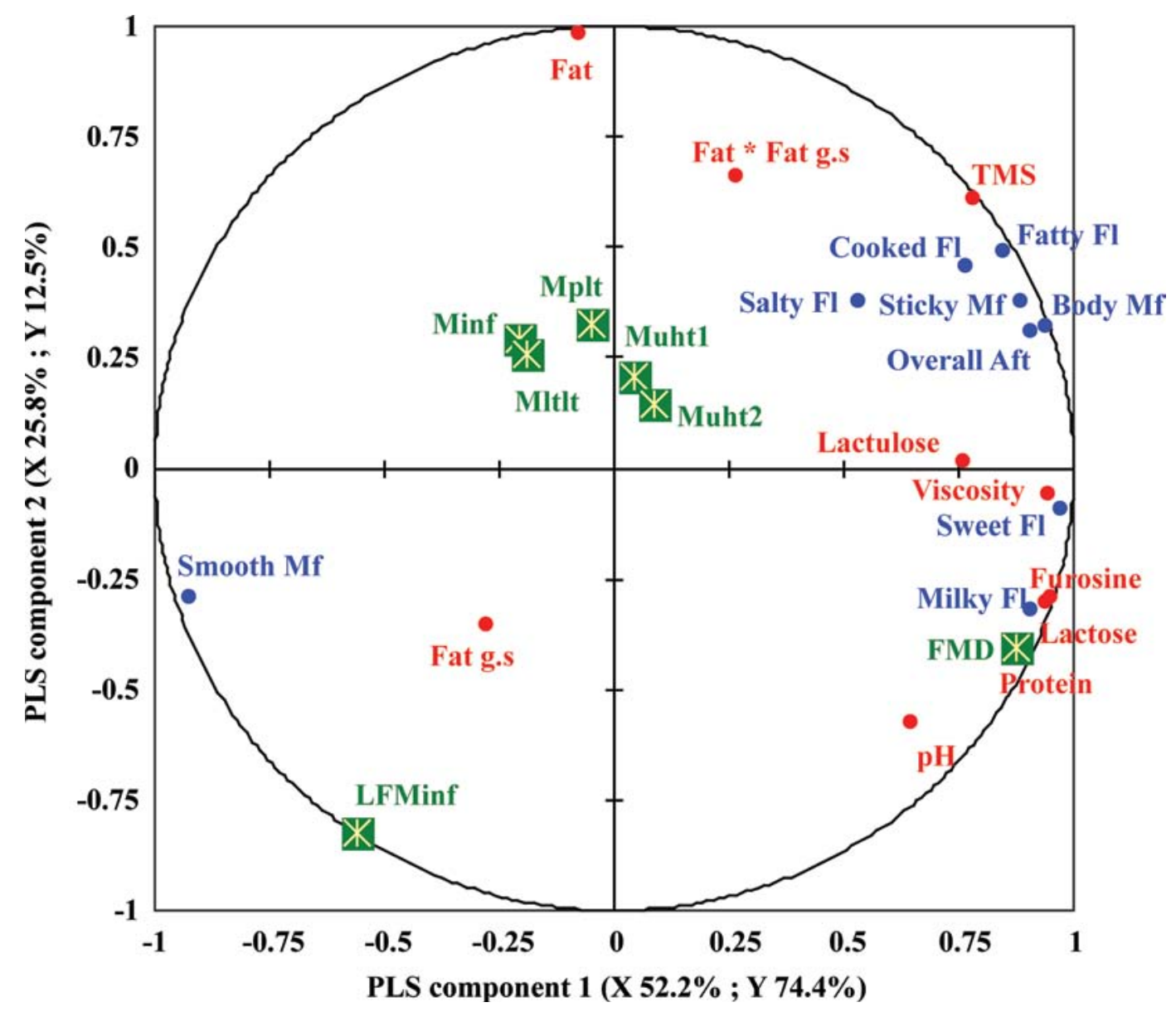

Figure 7. Correlation circle, for all 7 samples, of the sensory attributes (flavor, mouthfeel, and aftertaste), physicochemical parameters, and the products with (PLS component 1, PLS component 2). PLS = partial least squares; Mplt: full-cream milk, UHT plate heat exchanger sterilized; Minf: full-cream milk, UHT steam infusion sterilized; Muht1, Muht2: full-cream milk, supposed to be UHT plate heat exchanger sterilized, dissolved oxygen content reduced before sterilization; Mltlt: full-cream milk, low-temperature, long-time pasteurized; LFMinf: low-fat milk, UHT steam infusion sterilized; FMD: fermented milk drink Fat g.s: fat globule size; TMS: total milk solids. See Table 2 for descriptions of sensory attributes. Color version available in the online PDF.

and sweetness (Iwatsuki et al., 2001). Low-fat milk will have an advantage in many situations if its taste is richer and, as a result, some low-fat milk products may be produced with larger fat globules. Therefore, in this study, a term for the interaction between fat content and fat globule size, fat $\times$ fat GS, was introduced as a novel indicator to evaluate the total effect of fat.

Lactulose and furosine were adopted as markers of the extent of heating during production (Andrews, 1986; Erbersdobler, 1987). Although lactulose is a meaningful chemical indicator of heat loading for UHT sterilization, it is not effective for LTLT or HTST pasteurization (Geier and Klostermeyer, 1983; Akalin and Gonc, 1997; Morales et al., 2000).

Shown in Figure 5, a PLS correlation circle of full-fat milks was obtained in relation between aroma attributes and GC-MS data. This is because the different processing condition of full-fat milk is thought to be especially effective on aroma. In fact, in Figure 5, it is revealed that differences in sterilization methods give different GC-MS peaks and relationships to aroma characteristics. With respect to the relationship between other sensory attributes (flavor, mouthfeel, and aftertaste) and physicochemical properties, Figure 7 shows large differences between low-fat milk, full-fat milk as a group, and the fermented milk drink. In this case, even if full-fat milks, which have largely the same composition, were adopted, little significant information could be obtained. Therefore, the relationship between sensory characteristics and each component or physicochemical property will be determined in the sensory space and physicochemical scale made by full-fat milks, low-fat milk, and the fermented milk drink.

The importance of each component or physicochemical property can be quantitatively compared on a scatter plot of factor loadings as shown in Figure 8. In 

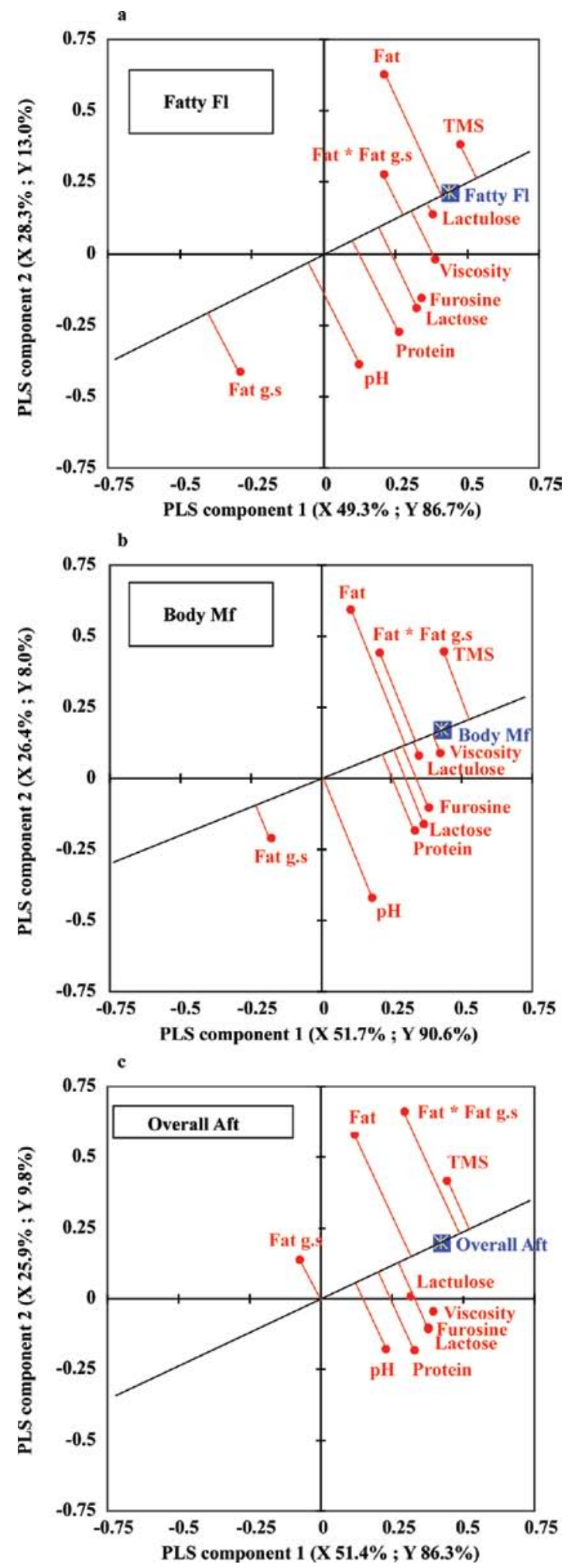

Figure 8. Partial least squares (PLS) loading plots, based on all 7 samples, of a) fatty flavor, b) body mouthfeel, and c) overall aftertaste as examples of physicochemical parameters related to flavor, mouthfeel, and aftertaste. Fat g.s: fat globule size; TMS: total milk solids. See Table 2 for descriptions of sensory attributes. Color version available in the online PDF.
Figure 8 , for example, 3 sensory attributes are shown on the scatter plot of factor loadings obtained with the high-quality PLS regression model (the attributes are Fatty Fl, Body Mf, and Overall Aft); TMS, fat, and lactulose (markers of the extent of heating) were positively related to Cooked Fl (not shown in Figure 8). This reflects the facts as follows: 1) the heating process has an effect on the developing cooked flavor as a matter of course, and 2) low-fat milk sterilized by steam infusion UHT sample had an extremely low Cooked Fl. All of the PLS models, based on the composition and physicochemical properties of each attribute, show a high predictability $\left(\mathrm{R}^{2}>0.93 ; \mathrm{R}^{2}\right.$ for cross-validation $>0.72$ ). As shown in Figure 8, TMS, fat, lactulose, viscosity, and fat $\times$ fat GS, in this order, were positively related to Fatty Fl; TMS, viscosity, fat $\times$ fat GS, lactulose, furosine, lactose, and protein, in this order, were positively related to Body Mf; and TMS, fat $\times$ fat GS, fat, viscosity, lactulose, and furosine, in this order, were positively related to Overall Aft.

Table 5 shows the contributors to these sensory attributes extracted from the PLS loading plot. Total milk solids was the main contributor to 4 attributes: Fatty Fl, Body Mf, Sticky Mf, and Overall Aft. Total milk solids contain protein, fat, carbohydrate (mainly lactose), and ash; therefore, it can be suggested that the components contribute to each attribute. The results show that the negative factors for Smooth Mf are almost the opposite of the positive factors for Sticky Mf. For Body Mf and Sticky Mf, these components contribute equally, whereas fat (fat content) is important for Fatty Fl and Overall Aft. Fat GS and fat are of the opposite sign shown in Fatty Fl, Body Mf, Sticky Mf, and Smooth Mf, which is eccentric. To design research to evaluate the correct contribution of fat in milk, it is important to have a term for the interaction between fat content and fat globule size; therefore, fat $\times$ fat GS is introduced.

Unexpectedly, viscosity was the main contributor to Sweet Fl, followed by protein and lactose. For Milky $\mathrm{Fl}$, protein was the first and lactose was the second contributor. Thus, it could be suggested that Sweet Fl is a sensation derived from Milky Fl and has longer residence time in the mouth because of its viscosity.

Correlating physicochemical properties with each sensory attribute, based on PLS factor loadings, is less simple than correlating volatile compounds with each aroma attribute. We can conclude that lactulose and furosine (as indicators of heating), as well as viscosity, were parameters that influenced all flavors, mouthfeels, and aftertaste, and Overall Aft was significantly related to the fat content.

If the full-cream milk samples, low-fat milk, and fermented milk drink, which have very different compo- 
Table 4. Peaks and volatile compounds selected by partial least squares, based on all 7 samples, as positively correlated with Overall Ar, Butter Ar, and Cooked $\mathrm{Fl}^{1}$

\begin{tabular}{|c|c|c|c|c|c|}
\hline \multicolumn{2}{|r|}{ Overall Ar } & \multicolumn{2}{|r|}{ Butter Ar } & \multicolumn{2}{|r|}{ Cooked Fl } \\
\hline Peak no. & Compound & Peak no. & Compound & Peak no. & Compound \\
\hline 3 & 2-Propanone & 39 & Decanoic acid & 2 & Dimethyl sulfide \\
\hline 5 & 2-Butanone & 2 & Dimethyl sulfide & 3 & 2-Propanone \\
\hline 39 & Decanoic acid & 3 & 2-Propanone & 31 & 2-Undecanone \\
\hline 2 & Dimethyl sulfide & 31 & 2-Undecanone & 39 & Decanoic acid \\
\hline 11 & Dimethyl disulfide & 5 & 2-Butanone & 5 & 2-Butanone \\
\hline 6 & Ethanol & 11 & Dimethyl disulfide & 8 & 2-Pentanone \\
\hline 28 & Acetic acid & 37 & Octanoic acid & 15,24 & 2-Heptanone \\
\hline 30 & 1-Octanol & 21 & Acetoin & 11 & Dimethyl disulfide \\
\hline 10 & $\alpha$-Pinene & 15,24 & 2-Heptanone & 30 & 1-Octanol \\
\hline 23 & Methyl acetate & 8 & 2-Pentanone & 29 & Benzaldehyde \\
\hline 26 & 1-Heptanol & 28 & Acetic acid & 21 & Acetoin \\
\hline 40 & $\delta$-Dodecalactone & 10 & $\alpha$-Pinene & 37 & Octanoic acid \\
\hline 31 & 2-Undecanone & 23 & Methyl acetate & 17 & Pyrazine \\
\hline 1 & Acetaldehyde & 26 & 1-Heptanol & 10 & $\alpha$-Pinene \\
\hline 36 & Benzyl alcohol & 40 & $\delta$-Dodecalactone & 23 & Methyl acetate \\
\hline
\end{tabular}

${ }^{1}$ See Table 2 for descriptions of sensory attributes.

sitions, had not been used, statistical calibration of sensory attributes with physicochemical properties would have had little practical significance in this study.

\section{CONCLUSIONS}

Descriptive analysis and sensometric techniques were used to reveal the sensory profile of the latest repre- sentative commercial milk samples, including those with the familiar flavor, as well as the relationships between sensory characteristics and the instrumental data obtained by product analysis. A descriptive sensory profile of UHT milk by conventional plate heatexchanger sterilization was obtained, and the comparison of sensory characteristics between full-cream milk

Table 5. Physicochemical parameters selected by partial least squares, based on all 7 samples, as positively or negatively correlated with flavor, mouthfeel, and aftertaste ${ }^{1,2}$

\begin{tabular}{|c|c|c|c|c|c|c|}
\hline Sweet Fl & Milky Fl & Fatty Fl & Body Mf & Sticky Mf & Smooth Mf & Overall Aft \\
\hline $\begin{array}{l}\text { Viscosity } \\
\text { Protein } \\
\text { Lactose } \\
\text { TMS } \\
\text { Furosine } \\
\text { Fat } \times \text { fat GS } \\
\text { pH } \\
\text { Lactulose } \\
\text { Fat GS }\end{array}$ & $\begin{array}{l}\text { Protein } \\
\text { Lactose } \\
\text { Viscosity } \\
\text { Furosine } \\
\text { pH } \\
\text { Fat GS } \\
\text { TMS } \\
\text { Fat } \times \text { fat GS }\end{array}$ & $\begin{array}{l}\text { TMS } \\
\text { Fat } \\
\text { Lactulose } \\
\text { Viscosity } \\
\text { Fat } \times \text { fat GS } \\
\text { Furosine } \\
\text { Lactose } \\
\text { Protein }\end{array}$ & $\begin{array}{l}\text { TMS } \\
\text { Viscosity } \\
\text { Fat } \times \text { fat GS } \\
\text { Lactulose } \\
\text { Fat } \\
\text { Furosine } \\
\text { Lactose } \\
\text { Protein }\end{array}$ & $\begin{array}{l}\text { TMS } \\
\text { Lactulose } \\
\text { Viscosity } \\
\text { Fat } \\
\text { Fat } \times \text { fat GS } \\
\text { Furosine } \\
\text { Lactose } \\
\text { Protein }\end{array}$ & Fat GS & $\begin{array}{l}\text { TMS } \\
\text { Fat } \times \text { fat GS } \\
\text { Fat } \\
\text { Viscosity } \\
\text { Lactulose } \\
\text { Furosine } \\
\text { Lactose } \\
\text { Protein } \\
\text { pH }\end{array}$ \\
\hline \multicolumn{7}{|c|}{ Negatively correlated } \\
\hline
\end{tabular}

\footnotetext{
${ }^{1}$ See Table 2 for descriptions of sensory attributes.
}

${ }^{2} \mathrm{TMS}=$ total milk solids; fat GS $=$ fat globule size. 
samples with various pasteurization and sterilization processes was accomplished. The full-cream milk, lowfat milk, and fermented milk drink had very different compositions and showed distinct sensory properties. The sensory space expanded by these samples reflected the consumer's choice in the market. For milk samples with almost the same composition, differences in the pasteurization and sterilization method were mainly reflected by the content of volatile compounds, which contribute to aroma perception and to a distinctive overall sensory profile. Important physicochemical properties that affect many sensory attributes were lactulose and furosine (as indicators of heating) and viscosity. Overall aftertaste, which could impart a good or bad impression to the products, was significantly related to fat content. In the future, milk samples should be assessed in terms of likes and dislikes and sensory characteristics should be matched to clarify the sensory attributes that contribute to consumer preference. Such studies will allow manufacturers of milk and related drinks to respond quickly to consumer needs uncovered by market research and to create products with new characteristics, leading to significant advances and opportunities for this industry.

\section{REFERENCES}

Adahchour, M., R. J. J. Vreuls, A. van der Heijden, and U. A. T. Brinkman. 1999. Trace-level determination of polar flavor compounds in butter by solid-phase extraction and chromatographymass spectrometry. J. Chromatogr. A 844:295-305.

Akalin, A. S., and S. Gonc. 1997. Lactulose and 5-HMF contents in market milks. Milchwissenschaft 52:377-380.

Andrews, G. R. 1986. Formation and occurrence of lactulose in heated milk. J. Dairy Res. 53:665-680.

Blake, M. R., B. C. Weimer, D. J. Mcmahon, and P. A. Savello. 1995. Sensory and microbial quality of milk processed for extended shelf life by direct steam injection. J. Food Prot. 58:1007-1013.

Chapman, K. W., and K. J. Boor. 2001. Acceptance of 2\% ultrapasteurized milk by consumers, 6 to 11 years old. J. Dairy Sci. 84:951-954.

Chapman, K. W., H. T. Lawless, and K. J. Boor. 2001. Quantitative descriptive analysis and principal component analysis for sensory characterization of ultrapasteurized milk. J. Dairy Sci. 84:12-20.

Contarini, G., and M. Povolo. 2002. Volatile fraction of milk: Comparison between purge and trap and solid phase microextraction techniques. J. Agric. Food Chem. 50:7350-7355.

Contarini, G., M. Povolo, R. Leardi, and P. M. Toppino. 1997. Influence of heat treatment on the volatile compounds of milk. J. Agric. Food Chem. 45:3171-3177.

Elliott, A. J., N. Datta, B. Amenu, and H. C. Deeth. 2005. Heatinduced and other chemical changes in commercial UHT milks. J. Dairy Res. 72:442-446.

Erbersdobler, H. F. 1987. Determination of furosine in heated milk as a measure of heat intensity during processing. J. Dairy Res. $54: 147-151$.

Fenaille, F., P. Visani, R. Fumeaux, C. Milo, and P. A. Guy. 2003. Comparison of mass spectrometry-based electronic nose and solid phase microextraction gas chromatography-mass spectrometry technique to assess infant formula oxidation. J. Agric. Food Chem. 51:2790-2796.
Francis, L. L., D. H. Chambers, S. H. Kong, G. A. Milliken, I. J. Jeon, and K. A. Schmidt. 2005. Serving temperature effects on milk flavor, milk aftertaste, and volatile compound quantification in nonfat and whole milk. J. Food Sci. 70:S413-S418.

Geier, H., and H. Klostermeyer. 1983. Formation of lactulose during heat treatment of milk. Milchwissenschaft 38:475-477.

Iwatsuki, K., H. Matsui, Y. Mizota, K. Sotoyama, M. Sumi, and M. Tomita. 2001. Effect of homogenizing pressure on physicochemical properties and sensory characteristics of UHT processed milk. Nippon Shokuhin Kagaku Kougaku Kaishi. 48:126-133.

Iwatsuki, K., Y. Mizota, T. Kubota, O. Nishimura, H. Masuda, K. Sotoyama, and M. Tomita. 1999a. Effect of pasteurization and UHT processing conditions on the sensory characteristics of milk. Nippon Shokuhin Kagaku Kougaku Kaishi. 46:587-597.

Iwatsuki, K., Y. Mizota, M. Sumi, K. Sotoyama, and M. Tomita. 1999b. Evaluation of aroma of pasteurized and UHT processed milk by aroma extract dilution analysis. Nippon Shokuhin Kagaku Kougaku Kaishi. 46:535-542.

Jeon, I. J., E. L. Thomas, and G. A. Reineccius. 1978. Production of volatile flavor compounds in ultrahigh-temperature processed milk during aseptic storage. J. Agric. Food Chem. 26:1183-1188.

Macfie, H. J., N. Bratchell, K. Greenhoff, and L. V. Vallis. 1989. Designs to balance the effect of order of presentation and firstorder carry-over effects in hall tests. J. Sens. Stud. 4:129-148.

Mikami, H., and Y. Ishida. 1983. Post-column fluorometric detection of reducing sugars in high performance liquid chromatography using arginine. Bunseki Kagaku 32:E207-E210.

Ministry of Health, Labor, and Welfare (Formerly Ministry of Health and Welfare Ordinance), Japan. 1951. Ministerial Ordinance on Milk and Milk Products Concerning Compositional Standards. Ministry of Health, Labor, and Welfare, Tokyo, Japan.

Moio, L., P. Etievant, D. Langlois, J. Dekimpe, and F. Addeo. 1994. Detection of powerful odorants in heated milk by use of extract dilution sniffing analysis. J. Dairy Res. 61:385-394.

Morales, F. J., C. Romero, and S. Jimenez-Perez. 2000. Characterization of industrial processed milk by analysis of heat-induced changes. Int. J. Food Sci. Technol. 35:193-200.

Phillips, L. G., M. L. McGiff, D. M. Barbano, and H. T. Lawless. 1995. The influence of nonfat dry milk on the sensory properties, viscosity, and color of lowfat milks. J. Dairy Sci. 78:1258-1266.

Pinho, O., C. Peres, and I. Ferreira. 2003. Solid-phase microextraction of volatile compounds in Terrincho ewe cheese. Comparison of different fibers. J. Chromatogr. A 1011:1-9.

Quinones, H. J., D. M. Barbano, and L. G. Phillips. 1998. Influence of protein standardization by ultrafiltration on the viscosity, color and sensory properties of $2 \%$ and $3.3 \%$ milk. J. Dairy Sci. 81:884894.

Stone, H., and J. L. Sidel. 2004. Descriptive analysis. Pages 201-244 in Sensory Evaluation Practices. 3rd ed. Elsevier Academic Press, San Diego, CA.

Stroup, W. H., R. W. Parker, and R. W. Dickerson Jr.. 1972. Steam infusion heater for ultra high temperature pasteurization. J. Dairy Sci. 55:536-539.

Vazquez-Landaverde, P. A., J. A. Torres, and M. C. Quian. 2006. Quantification of trace volatile sulfur compounds in milk by solidphase microextraction and gas chromatography-pulsed flame photometric detection. J. Dairy Sci. 89:2919-2927.

Vazquez-Landaverde, P. A., G. Velazquez, J. A. Torres, and M. C. Quian. 2005. Quantitative determination of thermally derived offflavor compounds in milk using solid-phase microextraction and gas chromatography. J. Dairy Sci. 88:3764-3772.

Watanabe, K., F. Nakamura, and K. Suyama. 1995. Analysis of furosine as an indicator of lysine residue glycation in milk protein by HPLC. Anim. Sci. Technol. 66:293-298.

Wold, S. 1995. PLS for multivariate linear modeling. Pages 195-218 in Chemometric Methods in Molecular Design. Wiley-VCH, Berlin, Germany. 